\title{
Impact of Source and Level of Calcium Fortification on the Heat Stability of Reconstituted Skim Milk Powder
}

\author{
H. K. Vyas and P. S. Tong \\ Dairy Products Technology Center \\ California Polytechnic State University \\ San Luis Obispo 93405
}

\begin{abstract}
Calcium enrichment of food and dairy products has gained interest with the increased awareness about the importance of higher calcium intake. Calcium plays many important roles in the human body. Dairy products are an excellent source of dietary calcium, which can be further fortified with calcium salts to achieve higher calcium intake per serving. However, the addition of calcium salts can destabilize food systems unless conditions are carefully controlled. The effect of calcium fortification on the heat stability of reconstituted skim milk was evaluated, using reconstituted skim milks with 2 protein levels: 1.75 and 3.5\% (wt/wt) prepared using low and high heat powders. Calcium carbonate, phosphate, lactate, and citrate were used for fortification at $0.15,0.18$, and $0.24 \%$ (wt/wt). Each sample was analyzed for solubility, heat stability, and $\mathrm{pH}$. The addition of phosphate and lactate salts lowered the $\mathrm{pH}$ of milk, citrate did not have any major effect, and carbonate for the $1.75 \%$ protein samples increased the $\mathrm{pH}$. In general, changes in solubility and heat stability were associated with changes in $\mathrm{pH}$. Calcium addition decreased the solubility and heat stability. However, interestingly, the presence of carbonate salt greatly increased the heat stability for $1.75 \%$ protein samples. This is due to the neutralizing effect of calcium carbonate when it goes into solution. The results suggested that the heat stability of milk can be affected by the type of calcium salt used. This may be applied to the development of milk-based calcium enriched beverages. (Key words: skim milk powder, calcium fortification, heat stability)
\end{abstract}

Abbreviation key: SI = solubility index.

\section{INTRODUCTION}

Calcium enrichment of food and dairy products is gaining more and more interest with the increased

Received March 12, 2003.

Accepted October 6, 2003.

Corresponding author: H. K.Vyas; e-mail: harit_vyas@hotmail.com. awareness about the importance of higher calcium intake. Calcium is the most abundant cation in the body and provides an exchangeable pool of calcium ions; maintains skeleton integrity, strength, and structure; and also plays important role in cellular metabolism, blood clotting, enzyme activation, and so on (Miller, 1989). The recommended dietary allowance for calcium in the United States is 800 and $1200 \mathrm{mg} / \mathrm{d}$ for children and adults, respectively (USAID, 1989).

Milk and dairy products are inherently considered an excellent source of dietary calcium. In cow's milk about $800 \mathrm{mg} \mathrm{L}^{-1}$ (about $2 / 3$ of the total calcium) are bound to casein micelles, either in a calcium phosphate salt (about $1 / 2$ of total milk calcium) or as calcium ions bound to phosphoserine residues (about 1/6 of total calcium); and about $370 \mathrm{mg} \mathrm{L}^{-1}$ is soluble or free calcium. Ionized calcium in soluble phase accounts for about $10 \%$ of total calcium and most remaining calcium occurs as calcium citrate (Walstra and Jenness, 1984; Holt, 1997). Milk products can be further enriched with calcium salts in order to achieve high calcium intake per serving. However, the addition of calcium salts can destabilize the milk proteins unless conditions are carefully controlled (Singh and Creamer, 1997; Cox and Miller, 2002). The levels of calcium in products like milk powder were observed to have a major effect on its functional properties (Cox and Miller, 2002). The physicochemical and functional properties of dry milk powders are important when the powders are used for recombining or as dairy-based ingredients in food fabrication (Singh and Newstead, 1997). Heat stability is an important attribute of milk powders used in hot beverages, custard, white sauce mixes, bakery items, and, most importantly, the manufacture of recombined milk products (e.g., evaporated milk). The effect of calcium ions on heat-induced gelation of recombined milk powders depends on the extent of preheat treatments (Newstead, 1977; Madkor and Fox, 1990). Solubility is a measure of the final condition to which the constituents of the powder can be brought into solution or stable suspension. Solubility is most directly affected by heat treatment during powder manufacture, levels of salt ions in the protein of milk powder, and heat 
stabilizing agent added to milk prior to manufacture (Singh and Newstead, 1997).

Thus, both the heat treatment during powder manufacture and the added calcium ions have effects on the solubility and heat stability of the milk powders. In the present study, the effects of heat treatment during the powder manufacture (high heat vs. low heat skim milk powder) were evaluated, as well as different sources and levels of calcium fortification on solubility and heat stability of reconstituted skim milk powders containing different protein levels.

\section{MATERIALS AND METHODS}

\section{Materials}

Low heat and high heat skim milk powders made from the same lot of skim milk were obtained (California Dairies, Inc., Eden Prairie, MN). Powders made from the same lot of skim milk were used to avoid variants between the 2 types of powders associated with different milk supplies. Calcium carbonate $\left(\mathrm{CaCO}_{3}\right)$, phosphate $\left(\mathrm{Ca}\left[\mathrm{H}_{2} \mathrm{PO}_{4}\right]_{2} \cdot \mathrm{H}_{2} \mathrm{O}\right)$, lactate $\left(\mathrm{C}_{6} \mathrm{H}_{10} \mathrm{CaO}_{6}\right.$ $\left.\cdot 5 \mathrm{H}_{2} \mathrm{O}\right)$, and citrate $\left(\mathrm{C}_{12} \mathrm{H}_{10} \mathrm{Ca}_{3} \mathrm{O}_{14} \cdot 4 \mathrm{H}_{2} \mathrm{O}\right)$ used for calcium fortification of the skim milk powders were laboratory grade (Spectrum Chemical Mfg. Corp., Gardena, $\mathrm{CA})$. Deionized water at room temperature $\left(20^{\circ} \mathrm{C}\right)$ was used to reconstitute the skim milk powders.

\section{Methods}

Calculated amounts of skim milk powder and calcium salt were mixed in a clean dry container, and then the mixture was reconstituted using the deionized water to bring the total mass of the sample to $100 \mathrm{~g}$. The samples were stored at $8^{\circ} \mathrm{C}$ overnight. Samples were analyzed for solubility index (SI), heat stability, and $\mathrm{pH}$. The SI was measured at $20^{\circ} \mathrm{C}$ using the method described by Sørensen (1978). Heat stability was measured by placing tightly closed glass test tubes containing $2 \mathrm{~mL}$ of sample at $20^{\circ} \mathrm{C}$ in the rocker of an oil bath maintained at $140^{\circ} \mathrm{C}$. Very clear and transparent silicone grade oil was used in the heating bath to ensure the proper visibility of the sample during heating. While being heated, the samples tubes were observed for the development of coagulation (curd flakes). Heat stability was expressed as the heating time required for the first appearance of curd flakes in each sample.

Four different calcium salts (calcium carbonate, calcium phosphate, calcium lactate and calcium citrate) and 3 usage levels $(0.15,0.18$, and $0.24 \%$, wt $/ w t)$ of calcium in reconstituted skim milk were studied. Two different sources (low heat and high heat skim milk powders) and 2 levels (1.75 and 3.5\%, wt/wt) of protein were used in this study. Control samples were prepared
Low Heat Powder

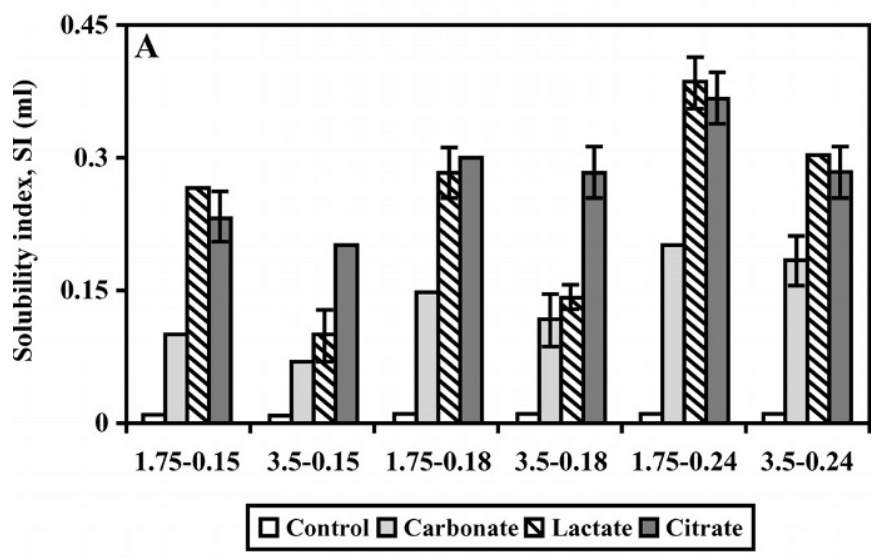

High Heat Powder

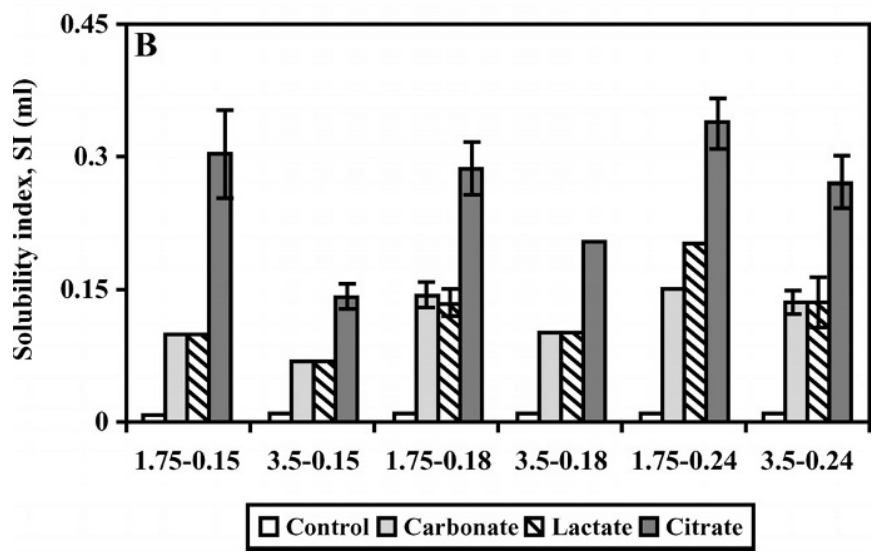

Figure 1. Effect of calcium fortification on the solubility of the reconstituted (a) low heat and (b) high heat skim milk powder with 1.75 and $3.5 \%$ protein levels.

using the 2 sources and 2 levels of protein without fortifying with calcium. The measured $\mathrm{pH}, \mathrm{SI}$, and heat stability of calcium-fortified samples were compared with that of the corresponding control samples. To further evaluate the effect of initial $\mathrm{pH}$ on the heat stability and to distinguish this effect from the neutralizing effect of the calcium salt, the $\mathrm{pH}$ of the control samples was increased to 7.15 from about 6.88 to 6.92 , and the $\mathrm{pH}$ of samples containing calcium carbonate was reduced to 6.88 from about 7.12 to 7.2 using $0.1 \mathrm{~N} \mathrm{NaOH}$ and $0.1 \mathrm{~N} \mathrm{HCl}$, respectively. These $\mathrm{pH}$-adjusted samples were then analyzed for the heat stability, and the results were compared with that of the control samples and calcium-fortified samples that were not $\mathrm{pH}$ adjusted. All experiments were carried out in triplicate. The chemical and physical analyses were done in duplicate. The means and standard deviations for each set of data were determined and expressed using bar charts and error bars (Figures 1 and 2). Noteworthy differ- 


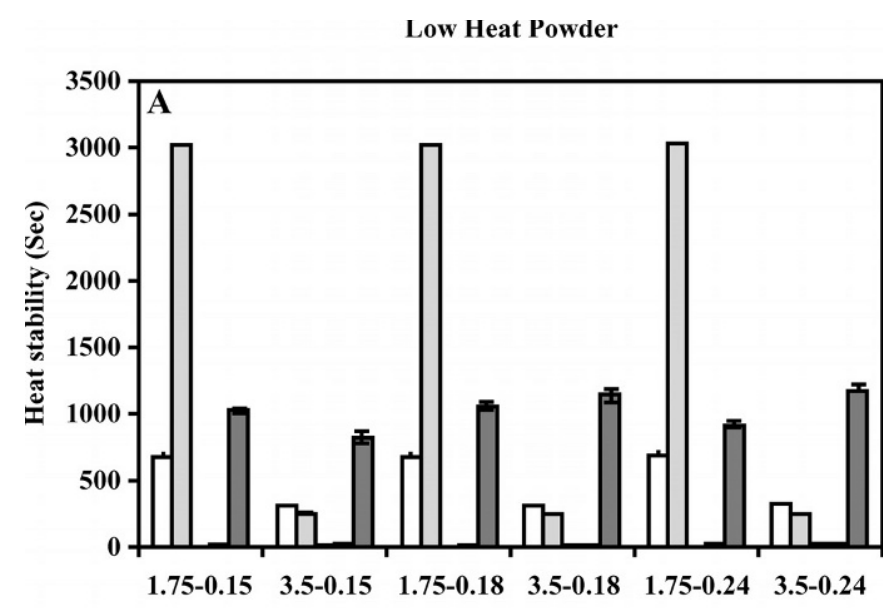

$\square$ Control $\square$ Carbonate $\mathbf{0}$ Phosphate $\Delta$ Lactate $\square$ Citrate

High Heat Powder

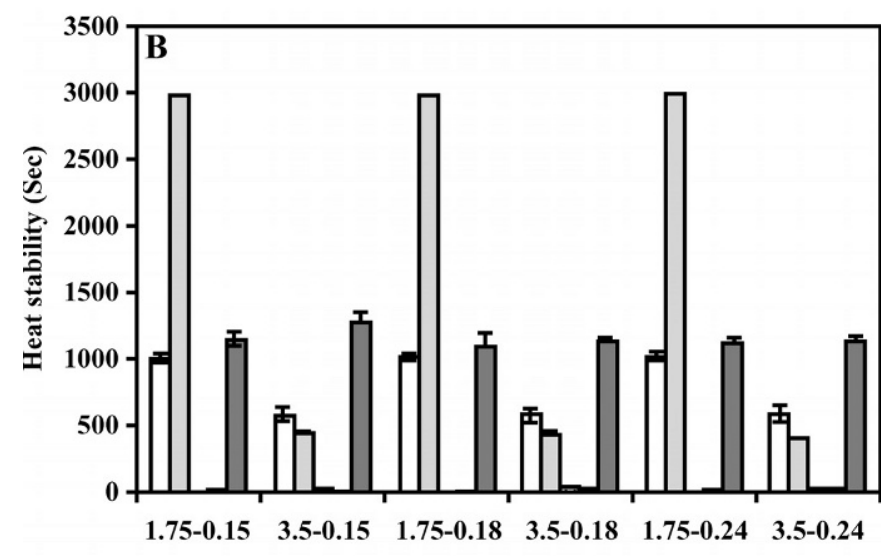

$\square$ Control $\square$ Carbonate $\mathbf{8}$ Phosphate $\mathbf{\Delta}$ Lactate $\square$ Citrate

Figure 2. Effect of calcium fortification on the heat stability of the reconstituted (a) low heat and (b) high heat skim milk powder with 1.75 and $3.5 \%$ protein levels. (Note: Heat stability values for the samples with phosphate and lactate salts were very low in the range of 0 to $18 \mathrm{~s}$ and are not visible.)

ences between treatment means were determined to be over 2 times the variance within a treatment.

\section{RESULTS AND DISCUSSION}

The powder samples fortified with calcium salts when reconstituted had different $\mathrm{pH}$ values than that of the control. The addition of calcium phosphate and lactate reduced the $\mathrm{pH}$, the addition of calcium citrate did not have any major effect, whereas the addition of calcium carbonate at a protein level of $1.75 \%$ increased the $\mathrm{pH}$. At the protein level of $3.5 \%$, the addition of calcium carbonate did not have any marked effect on the $\mathrm{pH}$.
The addition of phosphate salt in most of the cases lowered the $\mathrm{pH}$ below 6 and the samples curdled.

The SI values of different samples and controls for different combinations of protein and calcium sources, as well as calcium levels, are shown in Figure 1. It is important to note that the solubility index is expressed in milliliters of sediments or insoluble material. Thus, it is actually a measure of insolubility. Therefore, the higher the SI values are, the lower the solubility of the product. Samples containing phosphate salt were curdled so SI values are not reported here. There was no marked difference between the solubility of low heat and high heat powder control samples. However, for both types of powder, the trend in solubility tended to decrease (higher SI values) as calcium fortification level increased and protein level decreased.

Heat stability values for low heat and high heat skim milk powder samples are shown in Figure 2. A higher value for the heat stability is indicative of greater heat stability. (There was a longer time before the visible detection of coagulation during heating.) For the bar charts in Figures 1 and 2, due to a very small experimental run-to-run variation, the error bars (a measure of the standard deviation between replicates) often are not visible. As expected high heat control samples had a greater heat stability compared with low heat control samples. This effect has been associated with greater denaturation of whey proteins in high heat powder (Singh and Creamer, 1997; Singh and Newstead, 1997). The addition of phosphate or lactate salts caused immediate instability of the samples (zero heat stability, because they were curdled on reconstitution), whereas the addition of citrate salts tended to increase the heat stability. The addition of carbonate salts tended to decrease the heat stability for the samples with $3.5 \%$ protein compared with control samples. Interestingly, the heat stability of the $1.75 \%$ protein samples with carbonate salts increased to almost an indefinite level. There was no coagulation observed even after $3000 \mathrm{~s}$ (50 min) for any reconstituted milk containing $1.75 \%$ protein and fortified with calcium carbonate. While type of calcium salt affected the heat stability of the samples, varying the level of fortification in the studied range did not have any noticeable effect on the trends observed in heat stability.

Further work was focused on the samples with carbonate salts and $1.75 \%$ proteins due to the enormous increase in their heat stability compared with the control. The obtained values of solubility and heat stability were correlated with the $\mathrm{pH}$ of the reconstituted samples as shown in Figure 3. This analysis revealed that the higher the sample $\mathrm{pH}$ was, the greater the solubility and the heat stability. All the samples with carbonate salts and $1.75 \%$ protein, which had very high heat sta- 


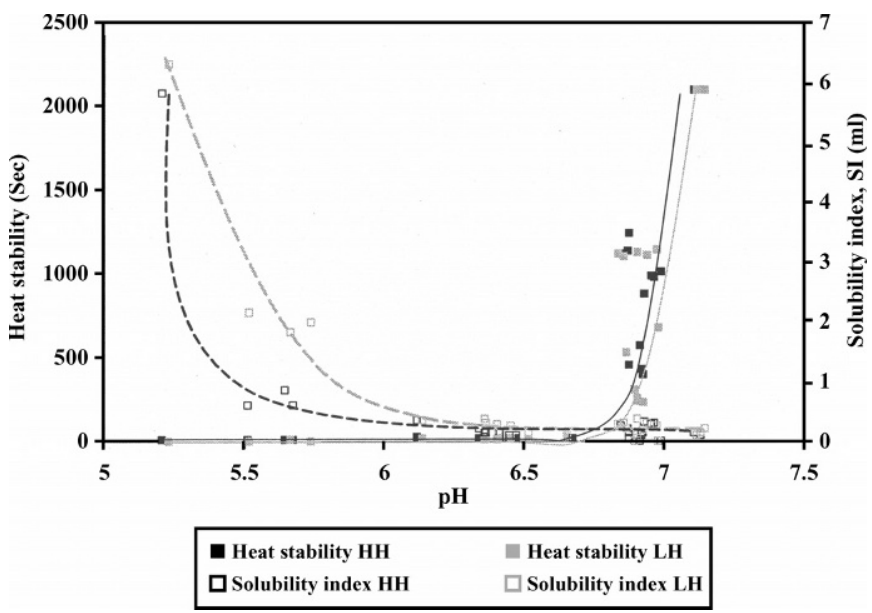

Figure 3. Correlation between the solubility and heat stability and the $\mathrm{pH}$ of the calcium fortified reconstituted high heat $(\mathrm{HH})$ and low heat (LH) skim milk powder samples.

bility, had a higher $\mathrm{pH}(\sim 7.2)$ compared with the control samples ( 6.9). To determine the contribution of the $\mathrm{pH}$ of the sample to the heat stability, the $\mathrm{pH}$ of the control was increased from $\sim 6.9$ to 7.2 and the $\mathrm{pH}$ of the samples with carbonate salts and $1.75 \%$ protein were decreased from $\sim 7.2$ to 6.88 . When these $\mathrm{pH}$ adjusted control and samples were analyzed for heat stability, the heat stability for the control changed to some extent (from 1016 to $922 \mathrm{~s}$, that is about a $9 \%$ decrease and 677 to $820 \mathrm{~s}$, that is about a $17 \%$ increase, for high heat and low heat controls, respectively), but there was no observed change in the heat stability of the samples (no coagulation after $3000 \mathrm{~s}$ ). However, the $\mathrm{pH}$ of these samples after $3000 \mathrm{~s}$ was higher (6.1 to 6.5) than that of the $\mathrm{pH}$ adjusted control after coagulation time, that is 922 and $820 \mathrm{~s}(\sim 5.25$ and $\sim 6.25)$ for high heat and low heat control, respectively.

The $\mathrm{pH}$ of milk decreased to between 5.5 and 6.0 at the point of coagulation in all samples during these studies. The $\mathrm{pH}$ of the milk during heating drops due to several reasons: (1) release of $\mathrm{CO}_{2},(2)$ precipitation of calcium phosphate and release of $\mathrm{H}^{+}$, and (3) formation of organic acids from thermal breakdown of lactose (Walstra and Jenness, 1984; Singh and Creamer, 1997). In the present study, the $\mathrm{pH}$ did not drop over a long period of time during heating in the case of samples with calcium carbonate. This is due to the neutralizing effect of the calcium carbonate going into the solution. This may in part explain the observed higher heat stability of samples fortified with calcium carbonate.

\section{CONCLUSIONS}

Calcium fortification of the skim milk powders by addition of citrate and carbonate salts improves heat stability. The presence of calcium carbonate in the reconstituted skim milk powder with $1.75 \%$ protein level greatly improves the heat stability. This may be partially due to the neutralizing effect of calcium carbonate when it goes into solution. Thus the heat stability of reconstituted milk powder can be affected by the source and level of calcium fortification.

\section{ACKNOWLEDGMENTS}

We would like to thank Dairy Management, Inc., Rosemont, IL, and California Dairy Research Foundation, Davis, CA, for the financial support.

\section{REFERENCES}

Cox, S. D., and J. L. Miller. 2002. Interactions of precipitated calcium carbonate (PCC) with proteins in the calcium fortification of dairy and non-dairy beverages. Page 34 in Technical Program Abstracts, Institute of Food Technologists, Chicago, IL.

Holt, C. 1997. The milk salts and their interaction with casein. Pages 233-256 in Advanced Dairy Chemistry. 1. Lactose, Water, Salts, and Vitamins. P. F. Fox, ed. Blackie Academic \& Professional Publishers, New York, NY.

Madkor, S. A., and P. F. Fox. 1990. Heat-induced gelation of concentrated reconstituted milk powder. 19th Food Sci. Technol. Res. Conf., Cork. Irish J. Food Sci. Technol., 13:139.

Miller, D. D. 1989. Calcium in the diet: food sources, recommended intakes and nutritional bioavailability. Adv. Food Nutr. Res. 33:103-156.

Newstead, D. F. 1977. Effect of protein and salts concentrations on the heat stability of evaporated milk. N.Z. J. Dairy Sci. Technol. 12:171-175.

Singh, H., and L. K. Creamer. 1997. Heat stability of milk. Pages 621-656 in Advanced Dairy Chemistry. I. Proteins. P. F. Fox, ed. Blackie Academic \& Professional Publishers, New York, NY.

Singh, H., and D. F. Newstead. 1997. Aspects of proteins in milk powder manufacture. Pages 735-765 in Advanced Dairy Chemistry. 1. Proteins. P. F. Fox, ed. Blackie Academic \& Professional Publishers, New York, NY.

Sørensen, H. 1978. Determination of solubility index. Pages 22-23 in Analytical Methods for Dry Milk Products. Niro Atomizer Dairy Research Group ed. A/S Niro Atomizer, Copenhagen, Denmark.

United States Agency for International Development. 1989. US Recommended Dietary Allowance, Commodities Reference Guide.

Walstra, P., and R. Jenness. 1984. Salts. Pages 42-57 in Dairy Chemistry and Physics. Wiley \& Sons Publishers, New York, NY. 